\title{
In vivo MRI assessment of permanent middle cerebral artery occlusion by electrocoagulation: pitfalls of procedure
}

\author{
Fabien Chauveau ${ }^{1 \dagger}$, Samir Moucharrafie ${ }^{2 \dagger}$, Marlène Wiart ${ }^{1}$, Jean-Christophe Brisset ${ }^{1}$, Yves Berthezène ${ }^{1}$, \\ Norbert Nighoghossian ${ }^{1,2^{*}}$, Tae-Hee $\mathrm{Cho}^{2}$
}

\begin{abstract}
Permanent middle cerebral artery (MCA) occlusion (PMCAO) by electrocoagulation is a commonly used model but with potential traumatic lesions. Early MRI monitoring may assess PMCAO for non-specific brain damage. The surgical steps of pMCAO were evaluated for traumatic cerebral injury in 22 Swiss mice using diffusion and T2-weighted MRI (7T) performed within $1 \mathrm{~h}$ and $24 \mathrm{~h}$ after surgery. Temporal muscle cauterization without MCA occlusion produced an early T2 hyperintensity mimicking an infarct. No lesion was visible after temporal muscle incision or craniotomy. Early MRI monitoring is useful to identify non-specific brain injury that could hamper neuroprotective drugs assessment.
\end{abstract}

\section{Introduction}

Investigating cerebral ischemia requires animal models relevant to human stroke. A precise knowledge of the strengths and shortcomings of available models is mandatory for effective research in neuroprotection [1,2]. Initially described in the rat [3] and subsequently adapted in mice [4], permanent middle cerebral artery (MCA) occlusion (pMCAO) by electrocoagulation is a widely used model of focal ischemia. Invasive surgical procedures are required: temporal muscle dissection, in some cases by electrical cauterization $[5,6]$, subtemporal craniotomy and MCA electrocoagulation. This model, by interrupting blood flow at the level of the parietal cerebral artery branch of the MCA (distal occlusion), has the advantage of producing smaller, cortical-restricted, more reproducible and bettertolerated infarcts compared to suture MCAO, which endoluminal occluder is situated in the internal artery, at the birth of the MCA (proximal occlusion) and gives rise to extensive cortico-striatal infarcts $[7,8]$. It may however induce traumatic brain damage.

To our knowledge, sham-operated animals have only been studied using immunohistology at the subacute

\footnotetext{
* Correspondence: norbert.nighoghossian@chu-lyon.fr

+ Contributed equally

'CREATIS, CNRS UMR 5220, INSERM U 630, Université Claude Bernard Lyon I,
} France without craniotomy nor MCA occlusion;

- group B $(n=4)$ : temporal muscle incision without craniotomy nor MCA occlusion;

- group $C(n=4)$ : temporal muscle incision followed by craniotomy without MCA occlusion;

- group D $(n=6)$ : temporal muscle incision followed by craniotomy and MCA electrocoagulation;

- group E $(n=2)$ : temporal muscle cauterization followed by craniotomy and MCA electrocoagulation. 
Craniotomy and MCA electrocoagulation were performed as previously described [9]. Whatever the group be, surgery was performed in less than $15 \mathrm{~min}$.

\section{MRI}

MRI experiments were performed on a $7 \mathrm{~T} / 12 \mathrm{~cm}$ magnet (Bruker BioSpin GmbH, Ettlingen, Germany) using a $72 \mathrm{~mm}$ inner diameter birdcage for RF transmission and a $15 \mathrm{~mm}$ diameter surface coil for reception. $\mathrm{T}_{2}$ weighted images $\left(\mathrm{T}_{2} \mathrm{WI}\right)$ were acquired using a RARE sequence with TE/TR $=75 / 3000 \mathrm{~ms}$. Diffusion weighted spin-echo images (DWI) were acquired with a TE/TR = $14 / 2000 \mathrm{~ms}$ using $2 \mathrm{~b}$-values (139 and $1061 \mathrm{~s} / \mathrm{mm}^{2}$ ). Apparent diffusion coefficients (ADC, in $\mathrm{mm}^{2} / \mathrm{s}$ ) were calculated by fitting a monoexponential model function on a pixel-by-pixel basis. The field of view was $20 \times 20$ $\mathrm{mm}^{2}$ and slice thickness $1.0 \mathrm{~mm}$. For $\mathrm{T}_{2} \mathrm{WI}, 15$ slices were acquired with $256 \times 256$ matrix and for DWI, 7 slices with $128 \times 128$ matrix. Mice anesthesia was maintained during the MRI with isofluorane (1.5\% in air). Body temperature was kept at $37 \pm 1^{\circ} \mathrm{C}$ with an integrated heating system, and a pressure probe monitored mice respiration. MRI was started immediately following the end of surgical procedure and all MR acquisitions were performed between $30 \mathrm{~min}$ and $60 \mathrm{~min}$ after the start of surgery. MRI was repeated on day 1 .

\section{Results}

Temporal muscle cauterization in the absence of MCA electrocoagulation (group A) consistently produced an extensive lesion across the frontoparietal cortex $(n=6 /$ 6). These lesions appeared hyperintense on $\mathrm{T}_{2} \mathrm{WI}$ within the first hour after surgery, with an early mass effect and reduced ADC (Figure 1A). Temporal muscle incision and craniotomy in the absence of MCA electrocoagulation (group $\mathrm{B}$ and $\mathrm{C}$, respectively) caused no visible brain injury on day 0 or day 1 MRI ( $n=4 / 4$ in groups $B$ and $C$, Figure $1 \mathrm{~B}$ and $1 \mathrm{C}$ ). MCA electrocoagulation (group D) induced an ischemic lesion in the frontoparietal cortex with reduced ADC on day $0(n=6 / 6)$. These lesions were not visible on $\mathrm{T}_{2} \mathrm{WI}$ within $1 \mathrm{~h}$ post-surgery (Figure 1D). No bleeding was noted during the surgery, but MCA electrocoagulation occasionally produced a small superficial traumatic lesion $(n=2 / 6$ in group $D$, figure $1 \mathrm{D})$. When pMCAO was performed using temporal muscle cauterization (group E), the lesion appeared as a superimposition of the almond-shaped cauterization lesion and of the MCA-territory bounded ischemic lesion ( $n=2 / 2$, Figure 2 ). Infarcts from group $\mathrm{A}, \mathrm{D}$ and $\mathrm{E}$ were clearly delineated on day $1 \mathrm{~T}_{2} \mathrm{WI}$.

\section{Discussion}

Our results showed that temporal muscle cauterization in the absence of ischemic stimulus produced a hyperintense area on $\mathrm{T}_{2}$ WI highly suggestive of traumatic injury. Indeed, $\mathrm{T}_{2}$ increase is not expected in ischemic lesions within the first hours of occlusion in adults, although early $\mathrm{T}_{2}$ increase has been reported in neonates after MCA electrocoagulation [10] or hypoxiaischaemia [11]. Early mass effect is uncommon after ischaemia in the adult rat [12] or mouse [13]. Acute ADC decrease is not specific of ischemic insult and has been described in both experimental and human traumatic brain injury $[14,15]$. Signal suggestive of intra- or extra-cranial surgery-related bleeding (T2 hypointensity)

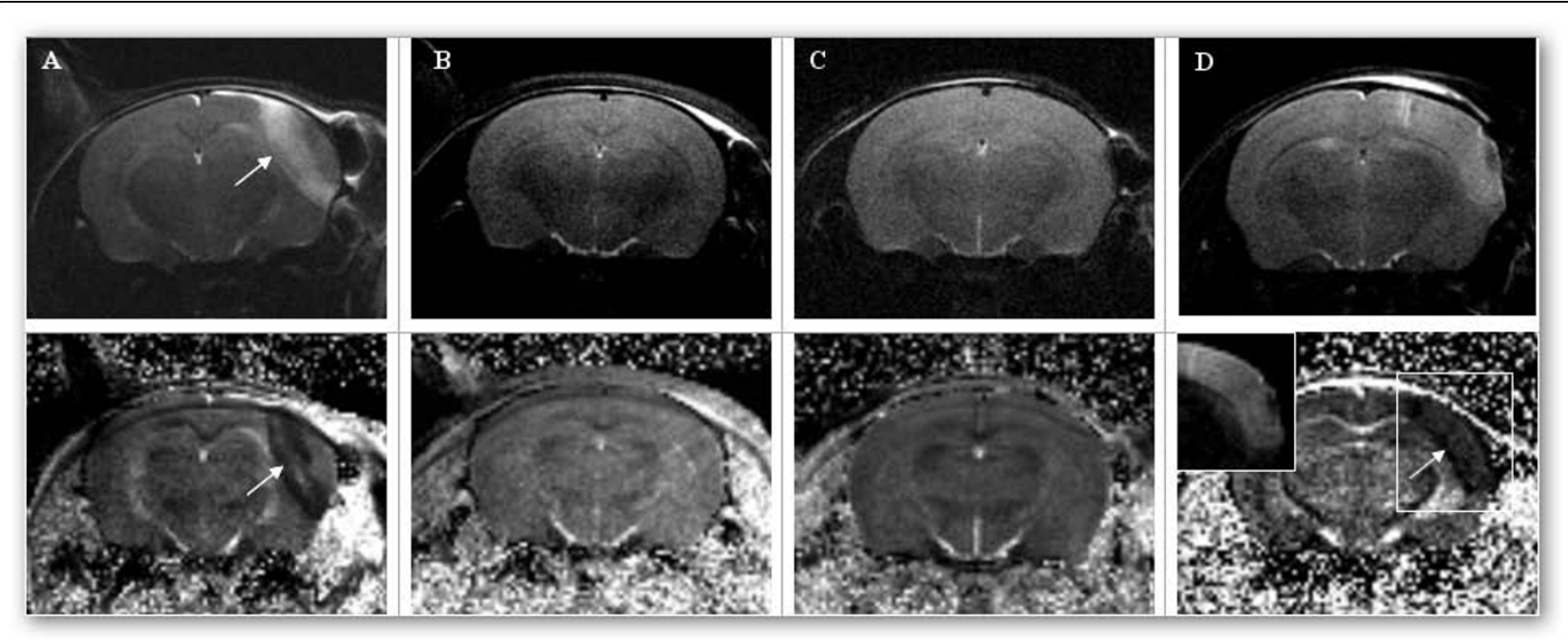

Figure 1 MRI within one hour of surgery: $\mathbf{T}_{\mathbf{2}} \mathbf{W I}$ (upper row) and ADC map (lower row). A: temporal muscle cauterization alone (group $A$ ). Note the lesion with early $\mathrm{T}_{2} \mathrm{WI}$ hyperintensity and reduced ADC (arrows). B: temporal muscle incision alone (group B). C: temporal muscle incision and craniotomy (group C). D: temporal muscle incision, craniotomy and MCA electrocoagulation. Note the ischemic lesion with low ADC (arrow) and normal $\mathrm{T}_{2} \mathrm{Wl}$ with a limited superficial traumatic lesion (arrow). 

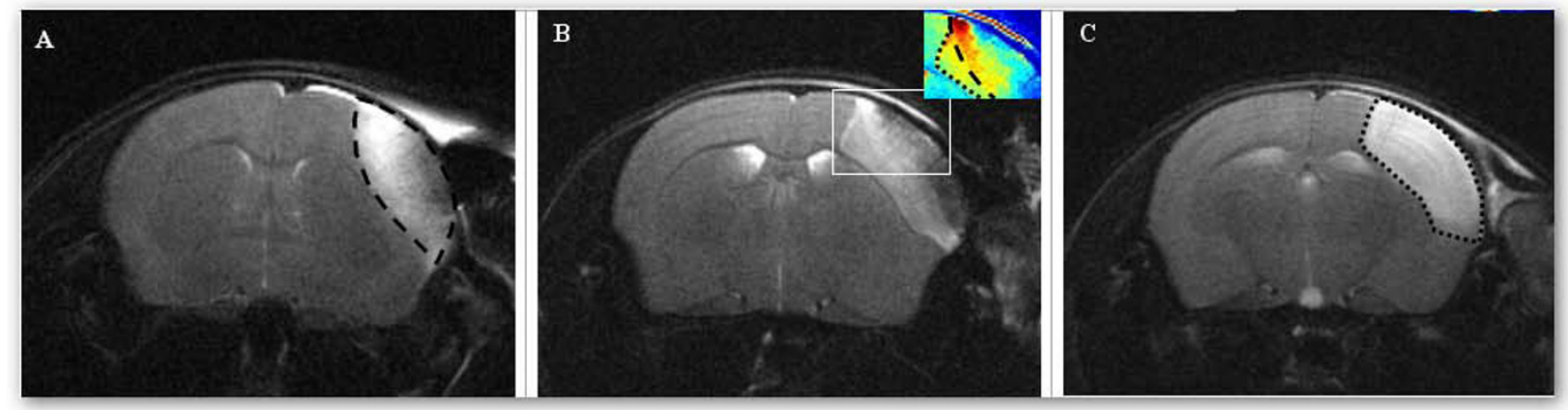

Figure 2 Impact of temporal muscle cauterization on pMCAO with $\mathbf{T}_{\mathbf{2}} \mathbf{W} \mathbf{I}$. A: temporal muscle cauterization alone (group A) showing day 0 traumatic lesion (interrupted lines). B: temporal muscle cauterization, craniotomy and MCA electrocoagulation (group E). Color-coded magnification shows the boundaries of the ischemic lesion (dotted line) and traumatic lesion (interrupted lines) $6 \mathrm{~h}$ after pMCAO. C: same mice at day 1 showing the limits of the final lesion (dotted line).

would have been ascertained using T2*WI, but were not noted. No traumatic injury was observed after temporal muscle incision. Accordingly, incision should be preferred over cauterization for temporal muscle dissection.

The MRI appearance of lesions resulting from both temporal muscle cauterization (traumatic damage) and occlusion (ischemic damage) may mimic an infarction, especially if imaging is done at later time points. Histopathological analyses are usually performed after a delay of 24-72 $\mathrm{h}$, when traumatic and ischemic damage may not be discernable, while early histological examination of intracerebral coagulation necrosis would be required to ascertain the thermal origin of traumatic damage induced by muscle cauterization.

In the last decade, high resolution MRI has become a valuable tool for monitoring tissue damage in rodent models of cerebral ischemia. Early MRI monitoring may help to identify non-specific brain injury that could hamper neuroprotective drugs assessment.

\section{Acknowledgements}

We are grateful to Jean-Baptiste Langlois, from the Small Animal Multimodal Imaging Facility, Animage (CERMEP, Lyon, France) for his help in MRI experiments.

\section{Author details \\ 'CREATIS, CNRS UMR 5220, INSERM U 630, Université Claude Bernard Lyon I, France. ${ }^{2}$ Cerebrovascular Unit, Hôpital Neurologique Pierre Wertheimer, Lyon, France.}

\section{Authors' contributions}

FC carried out the MRI experiments, participated in the design of the study and helped to draft the manuscript. SM carried out surgery. MW designed and optimized the MRI acquisition protocol, and helped to draft the manuscript. JCB participated in the MRI experiments. YB and NN conceived the study, and participated in its design and coordination. THC conceived the study, participated in its design, performed image analysis, and drafted the manuscript. All authors read and approved the final manuscript.

\section{Competing interests}

The authors declare that they have no competing interests.
Received: 10 December 2009

Accepted: 4 February 2010 Published: 4 February 2010

\section{References}

1. Gladstone DJ, Black SE, Hakim AM: Toward wisdom from failure: lessons from neuroprotective stroke trials and new therapeutic directions. Stroke 2002, 33:2123-2136.

2. Liu S, Zhen G, Meloni BP, Campbell K, Winn R: Rodent stroke model guidelines for preclinical stroke trials. J Exp Stroke Transl Med , 1 2009, 2:2-27.

3. Tamura A, Graham DI, McCulloch J, Teasdale GM: Focal cerebral ischaemia in the rat: 1 . Description of technique and early neuropathological consequences following middle cerebral artery occlusion. J Cereb Blood Flow Metab 1981, 1:53-60.

4. Welsh FA, Sakamoto T, McKee AE, Sims RE: Effect of lactacidosis on pyridine nucleotide stability during ischemia in mouse brain. $J$ Neurochem 1987, 49:846-851.

5. Boutin $H$, Dauphin F, MacKenzie ET, Jauzac P: Differential time-course decreases in nonselective, mu-, delta-, and kappa-opioid receptors after focal cerebral ischemia in mice. Stroke 1999, 30:1271-1277.

6. Herrmann O, Baumann B, de Lorenzi R, Muhammad S, Zhang W, Kleesiek J, Malfertheiner M, Kohrmann M, Potrovita I, Maegele I, Beyer C, Burke JR, Hasan MT, Bujard H, Wirth T, Pasparakis M, Schwaninger M: IKK mediates ischemia-induced neuronal death. Nat Med 2005, 11:1322-1329.

7. Carmichael ST: Rodent models of focal stroke: size, mechanism, and purpose. NeuroRx 2005, 2:396-409.

8. Durukan A, Tatlisumak T: Acute ischemic stroke: overview of major experimental rodent models, pathophysiology, and therapy of focal cerebral ischemia. Pharmacol Biochem Behav 2007, 87:179-197.

9. Pialat JB, Cho TH, Beuf O, Joye E, Moucharrafie S, Langlois JB, Nemoz C, Janier M, Berthezene Y, Nighoghossian N, Desvergne B, Wiart M: MRI monitoring of focal cerebral ischemia in peroxisome proliferatoractivated receptor (PPAR)-deficient mice. NMR Biomed 2007, 20:335-342.

10. Fau S, Po C, Gillet B, Sizonenko S, Mariani J, Meric P, Charriaut-Marlangue C: Effect of the reperfusion after cerebral ischemia in neonatal rats using MRI monitoring. Exp Neurol 2007, 208:297-304.

11. Qiao M, Latta P, Meng S, Tomanek B, Tuor UI: Development of acute edema following cerebral hypoxia-ischemia in neonatal compared with juvenile rats using magnetic resonance imaging. Pediatr Res 2004, 55:101-106.

12. Rudin M, Baumann D, Ekatodramis D, Stirnimann R, McAllister KH, Sauter A: MRI analysis of the changes in apparent water diffusion coefficient, T(2) relaxation time, and cerebral blood flow and volume in the temporal evolution of cerebral infarction following permanent middle cerebral artery occlusion in rats. Exp Neurol 2001, 169:56-63.

13. Barber PA, Hoyte L, Kirk D, Foniok T, Buchan A, Tuor U: Early T1- and T2weighted MRI signatures of transient and permanent middle cerebral artery occlusion in a murine stroke model studied at 9.4T. Neurosci Lett 2005, 388:54-59. 
14. Marmarou A, Signoretti S, Fatouros PP, Portella G, Aygok GA, Bullock MR: Predominance of cellular edema in traumatic brain swelling in patients with severe head injuries. J Neurosurg 2006, 104:720-730.

15. Unterberg AW, Stover J, Kress B, Kiening KL: Edema and brain trauma. Neuroscience 2004, 129:1021-1029.

doi:10.1186/2040-7378-2-4

Cite this article as: Chauveau et al:. In vivo MRI assessment of

permanent middle cerebral artery occlusion by electrocoagulation:

pitfalls of procedure. Experimental \& Translational Stroke Medicine 2010 2:4.

Submit your next manuscript to BioMed Central and take full advantage of:

- Convenient online submission

- Thorough peer review

- No space constraints or color figure charges

- Immediate publication on acceptance

- Inclusion in PubMed, CAS, Scopus and Google Scholar

- Research which is freely available for redistribution

Submit your manuscript at www.biomedcentral.com/submit 